\title{
PPI1: A Novel Pathogen-Induced Basic Region-Leucine Zipper (bZIP) Transcription Factor from Pepper
}

\author{
Sang Jik Lee, ${ }^{1}$ Mi Yeon Lee, ${ }^{1}$ So Young Yi, ${ }^{2}$ Sang Keun Oh, ${ }^{2}$ Soon Ho Choi, ${ }^{1}$ Nam Han Her, ${ }^{1}$ \\ Doil Choi, ${ }^{2}$ Byung Whan Min, ${ }^{1}$ Seung Gyun Yang, ${ }^{1}$ and Chee Hark Harn ${ }^{1}$ \\ ${ }^{1}$ Biotechnology Center, Nong Woo Bio Co., Ltd., 537-17 Jeongdan, Ganam, Yeoju, Kyonggi 469-885, Korea; \\ ${ }^{2}$ Genome Research Center, Korea Research Institute of Bioscience and Biotechnology, Taejon 305-600, Korea
}

Submitted 9 November 2001. Accepted 11 February 2002.

\begin{abstract}
We have isolated a full-length cDNA, PPII (pepper-PMMV interaction 1), encoding a novel basic region-leucine zipper (bZIP) DNA-binding protein, from expressed sequence tags differentially expressed in Capsicum chinense PI257284 infected with Pepper mild mottle virus (PMMV). PPII encodes a predicted protein of 170 amino acids and contains a putative DNA-binding domain that shares significant amino acid identity with ACGT-binding domains of members of the bZIP DNA-binding protein family. PPI1 was localized in the nucleus and had transcriptional activation activity in yeast. Transcripts of the PPI1 gene were preferentially induced during an incompatible interaction by inoculation with PMMV, Pseudomonas syringae pv. syringae 61, and Xanthomonas campestris pv. vesicatoria race 3. However, the PPI1 gene was not induced by abiotic stressors that activate the plant defense-signaling pathway. Our data provide the first evidence that a bZIP transcription factor is preferentially induced by pathogen attack, suggesting that PPI1 may play a specific functional role in the regulation of expression of plant defense-related genes.
\end{abstract}

Additional keywords: suppression subtractive hybridization.

Plants resist pathogen attack by activating a wide variety of defense mechanisms, including the hypersensitive response (HR), the induction of genes encoding pathogenesis-related (PR) and defense-related proteins, the production of antimicrobial compounds termed phytoalexins, the generation of reactive oxygen species (ROS), and the reinforcement of cell walls (Reymond and Farmer 1998).

In plants, transcriptional activation of numerous genes, modulated by DNA-binding proteins, plays a fundamental role in the response to pathogen infection (Rushton and Somssich 1998). However, very few transcription factors that respond specifically and directly to pathogens have been characterized in plants.

Eukaryotic transcription factors have been categorized into several families on the basis of their highly conserved DNAbinding domains. These include basic region-leucine zipper (bZIP) proteins, Myb-like proteins, MADS domain proteins, helix-loop-helix proteins, zinc-finger proteins, and homeo-box proteins (Meshi and Iwabuchi 1995; Schwechheimer et al. 1998). The bZIP DNA-binding proteins have been intensively

Corresponding author: Chee Hark Harn; Telephone: +82-31-883-7055; Fax: +82-31-884-7065; E-mail: chharn@ nongwoobio.co.kr studied because they play roles in the regulation of several biological processes such as seed-storage gene expression (Albani et al. 1997; Chern et al. 1996), photomorphogenesis (Oyama et al. 1997), leaf development (Yin et al. 1997), flower development (Chuang et al. 1999), abscisic acid (ABA) response (Nakagawa et al. 1996), and gibberellin biosynthesis (Fukazawa et al. 2000). In Arabidopsis, about 100 bZIP DNA-binding protein genes are present in the genome (Riechmann and Ratcliffe 2000). Recent studies show that several bZIP DNA-binding proteins appear to be indirectly involved in the plant defense response. For example, Arabidopsis NPR1-interacting protein (NIP) belongs to the TGA/ocs element-binding factor (OBF) family of bZIP factors that has been implicated in the activation of salicylic acid (SA)-responsive genes, including $P R-1$ (Zhou et al. 2000). In addition, the tobacco bZIP transcription factor, TGA2.2, is a major component of the activating sequence-1 (as-1)-binding factor (ASF-1) protein. This protein specifically binds to as- 1 , which is a functionally important element of SA-inducible defense genes such as PR-1a (Niggeweg et al. 2000). However, there have been very few reports on the direct induction of bZIP factors by plant pathogens.

In this study, we report the characteristics of a novel bZIP transcription factor, PPI1, from pepper. PPI1 is distinct from other bZIP family members. It shares a limited but significant amino acid homology to other bZIP factors, and its gene expression is preferentially induced following pathogen infection but not following exposure to abiotics such as SA, methyl jasmonate (MeJA), ethephon, $\mathrm{H}_{2} \mathrm{O}_{2}$, or ABA. We propose that PPI1 acts as a nuclear factor in a signaling pathway that activates plant defense responses against pathogen attack.

\section{RESULTS}

Isolation and amino acid sequence analysis of PPII.

To study the molecular mechanism controlling the plant defense response, we have identified by suppression subtractive hybridization (SSH) a broad spectrum of Pepper mild mottle virus (PMMV) (pathotype $\mathrm{P}_{1,2}$ )-inducible genes that are differentially expressed during an incompatible interaction possibly mediated by the $L^{3}$ resistance gene of Capsicum chinense PI257284. Differentially expressed cDNA clones (205) were isolated and sequenced, and 98 independent clones were obtained (data not shown). One partial cDNA fragment that showed amino acid homology to bZIP DNA-binding proteins was used as a probe to screen a cDNA library previously constructed from $C$. annuum (Lee et al. 2001). Five positive clones were isolated and the longest cDNA, designated PPII, was se- 
quenced completely. PPII was 1,216 base pairs (bp) long and the open reading frame (ORF) predicted a polypeptide of 170 amino acids with a calculated molecular mass of $19.4 \mathrm{kDa}$ (NCBI accession no. AF430372). Amino acid sequence analysis of PPI1 revealed that it was almost identical to the putative bZIP DNA-binding protein of $C$. chinense (NCBI accession no. AF127797) (Fig. 1). The only amino acids missing in AF127797 were a triplet of asparagines (amino acids at position 117 to 119 of PPI1). The deduced PPI1 protein was found to be homologous to various plant bZIP DNA-binding proteins, which are shown in Figure 1. The Arabidopsis ATB2 (NCBI accession no. AF053940) (Rook et al. 1998) and the tobacco BZI-2 (NCBI accession no. AY045570) (Strathmann et al. 2001) are the best-characterized members among them. PPI1 showed sequence similarity to other bZIP DNA-binding proteins from Arabidopsis thaliana (NCBI accession nos. AF053939 and AF053940; 42 and 50\%, respectively), Petroselinum crispum (NCBI accession nos. AJ292744 and AJ292745; 38 and 49\%, respectively), Zea mays (NCBI accession no. X62745; 29\%), Lycopersicon esculentum (NCBI accession no. AF176641; $35 \%$ ), Nicotiana tabacum (NCBI accession nos. AY045570 and $\mathrm{AB} 032478 ; 84$ and 38\%, respectively), and Antirrhinum majus (NCBI accession nos. Y13675 and Y13676; 34 and $38 \%$, respectively). The overall amino acid sequence identity between PPI1 and other bZIP proteins, except for AF127797, ranged from 29 to $84 \%$, whereas the amino acid identity within their basic and leucine zipper domains (amino acids at position 33 to 112 of PPI1) ranged from 45 to $92 \%$. This region is also known to contain the ACGT recognition motif of plant bZIP factors. This basic motif generally binds to the ACGT core sequence present in the promoters of bZIP-responsive genes, implying that PPI1 is an ACGT-binding factor. There is also an acidic C-terminal region (amino acids at position 113 to 170) that is probably similar in function to acidic activation domains of other transcription factors, suggesting that PPI1 might act as a transcriptional activator.

\section{PPI1 is exclusively localized to the nucleus.}

The nuclear localization signal (NLS) sequence $\left({ }^{33} \mathrm{KRMISNRESARRSRMRK}^{49}\right)$ of PPI1 is almost identical to the NLS of other bZIP proteins. To confirm the possibility that PPI1 acts as a nuclear factor, we examined the subcellular localization of the PPI1 protein. The ORF of PPI1 was fused to the upstream region of the soluble modified green fluorescent

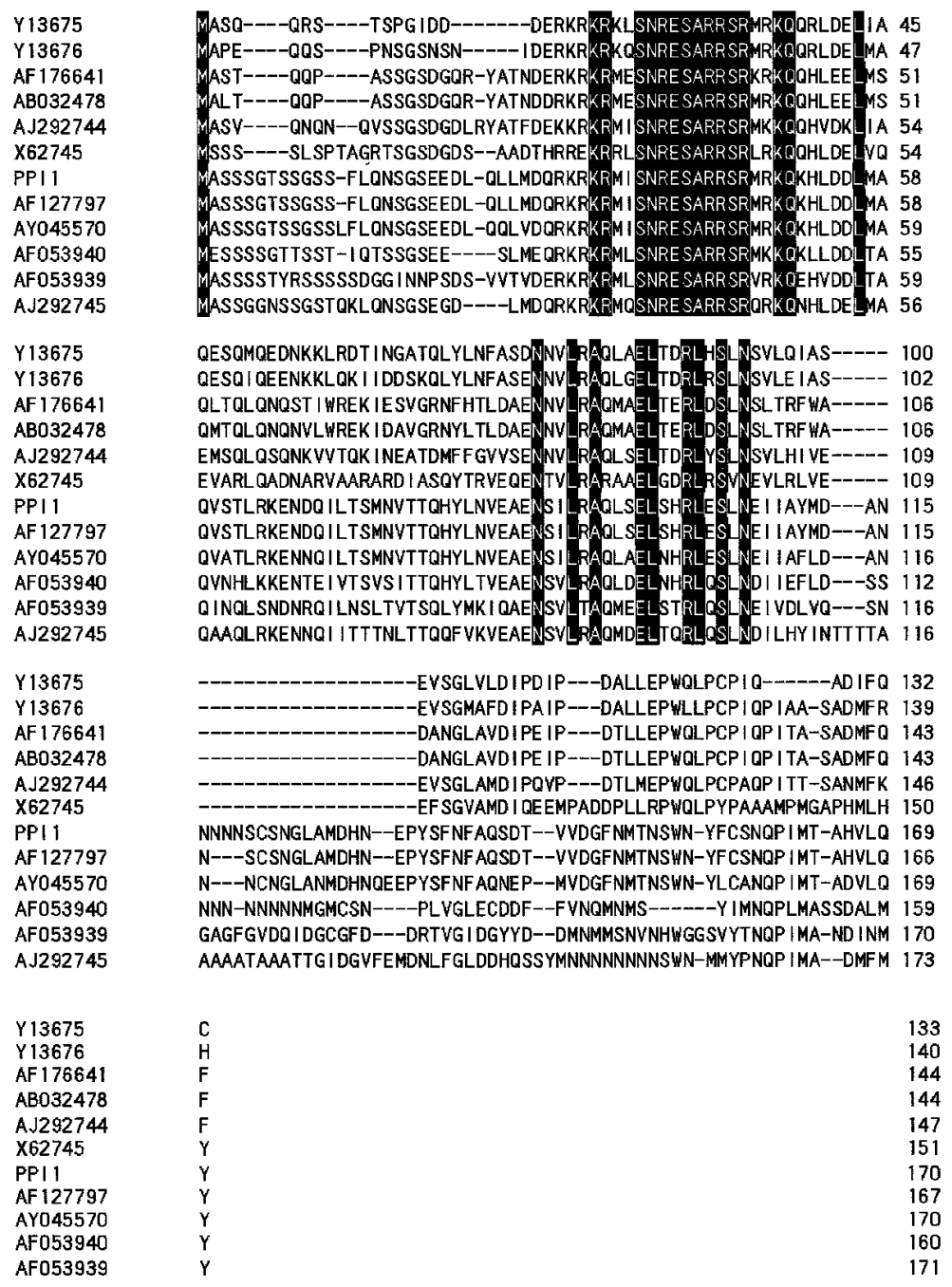

Fig. 1. Comparison of the amino acid sequences of PPI1 (NCBI accession no. AF430372) with other basic region-leucine zipper (bZIP) transcription factors. The dark gray boxes indicate identical residues in amino acid sequences. NCBI accession numbers are as follows: Y13675, bZIP DNA-binding protein from Antirrhinum majus; Y13676, bZIP DNA-binding protein from Antirrhinum majus; AF176641, LebZIP1 from Lycopersicon esculentum; AB032478, tbzF from Nicotiana tabacum; AJ292744, CPRF6 from Petroselinum crispum; X62745, OCSBF-1 from Zea mays; PPI1, this work; AF127797, putative bZIP DNA-binding protein from Capsicum chinense; AY045570, BZI-2 from Nicotiana tabacum; AF053940, ATB2 from Arabidopsis thaliana; AF053939, GBF5 from Arabidopsis thaliana; and AJ292745, CPRF7 from Petroselinum crispum. 
protein $(s m G F P)$ gene, which acted as a fluorescent marker. Fusion constructs $(35 S:: P P I 1-s m G F P)$ were introduced into onion epidermal cells by the particle bombardment system to transiently express smGFP or PPI1-smGFP under the control of the Cauliflower mosaic virus (CaMV) $35 \mathrm{~S}$ promoter, and protein localization was determined with a fluorescence microscope. As shown in Figure 2, the smGFP fusion protein was localized only to the nucleus, while the control smGFP was uniformly distributed throughout the cell. These results indicate that PPI1 is a nuclear factor.

\section{The acidic C-terminal region}

of PPI1 mediates transcriptional activation in yeast.

To determine if PPI1 was capable of activating the transcription of reporter genes in yeast, the DNA-binding domain of LexA (Clontech, Palo Alto, CA, U.S.A.) was fused to several constructs of PPI1 (PPI1F, residues at position 1 to 170 ; PPI1N1, position 1 to 68 ; PPI1N2, position 1 to 115 ; PPI1C1, position 81 to 170 ; and PPI1C2, position 110 to 170 ). The transcriptional activation of these constructs was identified by measuring activation of the $L E U 2$ and $L a c Z$ dual reporter genes under the control of the LexA operator in yeast (Fig. 3A). Yeast cells carrying the plasmids containing PPIN2 ( $\mathrm{pI}=8.12)$, PPIF ( $\mathrm{pI}=5.93)$, PPI1C1 ( $\mathrm{pI}=4.31)$, or PPI1C2 (pI = 4.03) grew on medium lacking leucine. In contrast, yeast cells carrying the plasmids containing PPI1N1 $(\mathrm{pI}=10.47)$ did not grow. Yeast strains that grew on the medium lacking leucine also induced LacZ activity and formed blue colonies in the presence of 5bromo-4-chloro-3-indolyl- $\beta$-D-galactopyranoside (X-Gal) (Fig. 3B). LexA-PPI1N2, LexA-PPI1F, LexA-PPI1C1, and LexAPPI1C2 activated the transcription of the reporter gene by 5.9-, 67.6-, 96.7-, and 82.1-fold compared with the negative control (LexA-Lam), respectively (Fig. 3C). The transcriptional activity of the positive control (LexA-GAL4) was 90.2-fold greater than that of the negative control (LexA-Lam). These observations are consistent with a previous report showing that bZIP DNA-binding proteins have transcriptional transactivation ac-

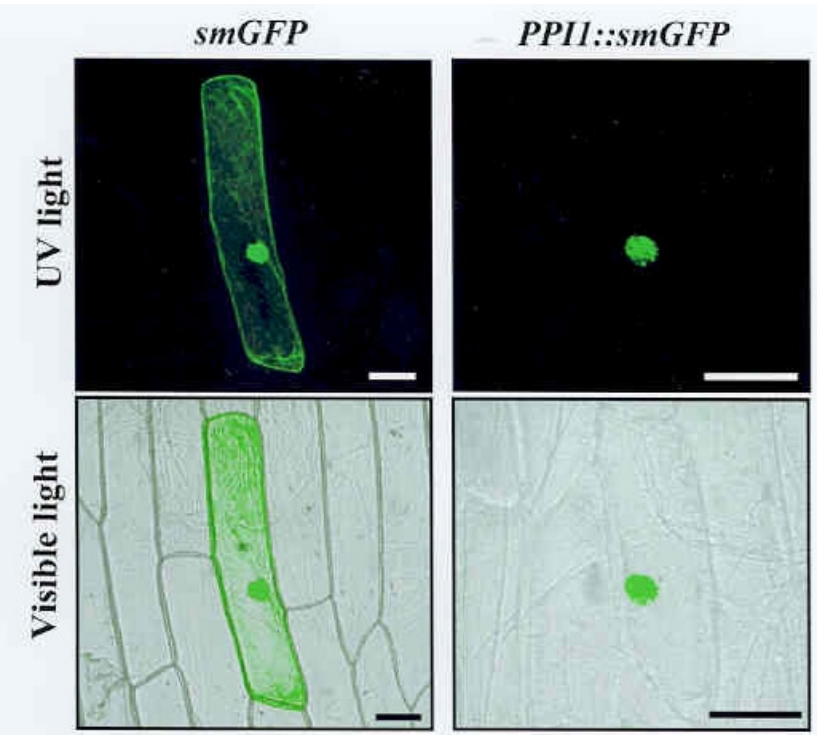

Fig. 2. Nuclear localization of PPI1. The PPII open reading frame was fused in-frame to the upstream region of the $s m G F P$ gene. Inner onion epidermal cells were transformed with the fusion constructs by bombardment, and the cells were examined under a confocal laser-scanning microscope (MRC-1024; Bio-Rad, Hercules, CA, U.S.A.) 16 h later. Onion cells transformed with the control smGFP are shown in the left panel. Onion cells transformed with PPI1-smGFP are shown in the right panel. The scale bars are $100 \mu \mathrm{m}$ long. tivity (Sprenger-Haussels and Weisshaar 2000). Thus, the acidic C-terminal region of PPI1 (residues at position 110 to 170) contains a potential transcriptional activation domain, which also provides strong evidence that PPI1 is a transcriptional activator.

\section{Genomic DNA blot analysis reveals one copy} of the PPI1 gene.

Genomic DNA isolated from C. chinense PI257284 was digested with DraI, EcoRI, HindIII, or XbaI. The blot was then hybridized with radioactively labeled PPI1 cDNA (1,216 bp). Only one band from each digestion was seen on the Southern blot (Fig. 4). This restriction pattern strongly suggested that the pepper genome contained a single copy of the PPII gene.

\section{Transcription levels of PPI1 in various tissues.}

To investigate the tissue specificity of PPIl transcription, RNA gel blot analysis was performed. Total RNA was isolated from leaves, stems, flower primordia, open flowers, fruit pericarps, fruit placenta, seeds, and roots of $C$. chinense PI257284, fractionated on a $1.0 \%$ agarose gel, and transferred to a membrane. The transferred membrane was hybridized with radioactively labeled PPII cDNA (1,216 bp). A 1.2-kilobase transcript was detected in open flowers and seeds at a low level and was very weakly present in stems and flower primordia. In comparison, the transcripts were undetectable in leaves and barely detectable in pericarps, placenta, and roots (Fig. 5).

\section{PPI1 gene induction patterns by PMMV,}

Pseudomonas syringae pv. syringae 61, and Xanthomonas campestris pv. vesicatoria race 3.

To study PPI1 gene expression in response to pathogen attack, we inoculated $C$. chinense PI257284, which carries the $L^{3}$ resistance locus, with PMMV (pathotype $\mathrm{P}_{1,2}$ ). Inoculated pepper leaves elicited the HR at 3 days postinoculation (data not shown). As shown in Figure 6A, PPII was expressed as early as $12 \mathrm{~h}$ after PMMV inoculation and its level increased at $24 \mathrm{~h}$ after inoculation. At $120 \mathrm{~h}$ after inoculation, the level of PPII expression decreased, while the level of the $P R-4 b$ (accession number BI894277) transcript remained high. The PPIl gene was not expressed when leaves were mock-inoculated with water.

When pepper leaves were infiltrated with $P$. syringae pv. syringae 61, a wheat pathogen, the leaves elicited the HR at $12 \mathrm{~h}$ postinfiltration (data not shown). PPII transcripts were detected as early as $3 \mathrm{~h}$ after infiltration (Fig. 6B), and their levels remained constant up until $24 \mathrm{~h}$ after infiltration. Expression of the $P R-4 b$ gene could be detected at $6 \mathrm{~h}$ postinfiltration, and its expression continued to increase over the time course of the experiment.

Furthermore, we studied the induction of PPII by inoculating the race 3 (avrBs 2 ) of $X$. campestris pv. vesicatoria. The expression pattern of the PPII gene in leaves was compared between the resistant line and the susceptible line, both nearisogenic pepper lines. The HR symptom was characteristic of avrBs 2 infection to pepper plants, and the $B s 2$ gene conferred resistance (Tai et al. 1999). Susceptible plants infiltrated with race 3 of $X$. campestris pv. vesicatoria did not exhibit any visible response within $36 \mathrm{~h}$ postinfiltration, whereas resistant plants developed an HR on infiltrated leaf tissue within $24 \mathrm{~h}$ postinfiltration (data not shown). As shown in Figure 6C, the PPIl transcript was induced within $8 \mathrm{~h}$ after infiltration with incompatible $X$. campestris pv. vesicatoria and the detectable levels of PPII transcripts remained steady thereafter.

Expression patterns of several PMMV-induced expressed sequence tags were similar to PPIl expression, regardless of the level of host resistance or nonhost response in this study (data 
not shown). This suggests that a common mechanism may be involved in the induction of gene expression by plant pathogens.

\section{Expression of $P P I 1$ is independent of abiotic signals.}

The accumulation of endogenous SA, ethylene, or MeJA is common to pathogen-infected plants. PPII transcript levels were examined after exogenous application of SA, ethephon, or MeJA to mature pepper leaves. We found that these compounds did not induce macroscopic cell death (data not shown). As shown in Figure 7A, these compounds also did not induce PPIl gene expression, whereas the expression of marker genes such as PR-1 (BI894280), ACC oxidase (BI894281), and proteinase inhibitor 2 (Pin2; BI894279) was induced. PR-1 mRNA could be detected within $6 \mathrm{~h}$ after SA treatment. In addition, the ACC oxidase gene and Pin2 were induced as early as $30 \mathrm{~min}$ after treatment with ethephon and MeJA. $\mathrm{H}_{2} \mathrm{O}_{2}$ and ABA did not induce expression of PPI1 during the $24 \mathrm{~h}$ after treatment, while the marker genes, GST (BI894278) and Dehydrin (a pepper homolog; provided by D. Choi), were highly expressed 1 to $3 \mathrm{~h}$ after treatment (Fig. 7B). Using the same hybridization conditions, the PPIl gene was strongly induced at $72 \mathrm{~h}$ after PMMV inoculation as a positive control (data not shown).

\section{DISCUSSION}

We report here the isolation and characterization of the bZIP DNA-binding protein gene, PPIl. The PPIl gene was preferentially expressed during incompatible interactions with PMMV, $P$. syringae pv. syringae 61 , and $X$. campestris pv. vesicatoria race 3. PPI1 is a nuclear protein and is capable of activating transcription in yeast. These results suggest that the PPI1 protein is a transcription factor that could be part of the plant defense response against pathogen infection.

PPIl is particularly interesting because it has characteristics different from those of other members of the bZIP DNA-binding protein family. First, PPII has a limited but significant amino acid sequence homology with other bZIP transcription factors (29 to $84 \%$ ) (Fig. 1). The PPI1 amino acid sequence exhibits the highest identity (84\%) with BZI-2 (Strathmann et al. 2001) of tobacco among the functionally characterized bZIP proteins to date. There was even low sequence similarity to the LebZIP1 protein from tomato (35\%) (Stanković et al. 2000), a member of the same solanaceous family. Second, transcripts of PPII are specifically up-regulated during an incompatible interaction between pepper and pathogens (Fig. 6A to C). To our knowledge, this is the first report showing that transcription of a bZIP DNA-binding protein gene is preferentially induced by pathogen infection. It would be interesting to determine if the PPII promoter mediates this pathogen-specific response. Third, treatment of pepper leaves with abiotic compounds such as SA, ethylene, MeJA, $\mathrm{H}_{2} \mathrm{O}_{2}$, and ABA did not induce PPIl gene expression (Fig. 7). Thus, expression of the PPII gene appears to be induced specifically by biotic stresses. This is surprising because bZIP DNA-binding proteins are induced by phytohormones such as ABA (Nakagawa et al. 1996) and also by other environmental conditions such as low temperature (Aguan et al. 1993), light (Rook et al. 1998), and wounding (Stanković et al. 2000). Fourth, although $P R$ genes were induced by most of the biotic and abiotic treatments that were shown previously to be effective for $P R$ gene induction (Dong 1998; Reymond and Farmer 1998), induction of PPII gene expression appears to be limited to pathogen infection in this study (Fig. 6A to C). Therefore, PPII gene induction may not be required for expression of the $P R$ genes. Our results suggest that $P P I 1$ may participate in a plant defense-signaling pathway, independent of the relatively well-characterized pathway that is activated in response to SA, ethylene, and MeJA.
The bZIP class of transcription factors has been extensively studied in plants. Plant bZIP proteins share a highly conserved basic domain and bind to target sequences usually containing the G-box ACGT element (Dröge-Laser et al. 1997; Foster et al. 1994; Menkens et al. 1995). Based on sequence analysis, PPII also possesses a highly conserved DNA-binding domain, which may bind the G-box element within promoters.

Nuclear proteins that contain NLS sequences are specifically recognized by receptors and are imported through the nuclear pore complexes into the nucleus (Görlich 1997). NLS sequences are integral parts of nuclear protein structures and usually consist of short sequences with a high proportion of basic amino acids. The PPI1-smGFP fusion protein was found exclusively in the nu-

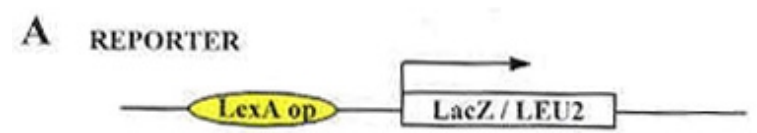

\section{EFFECTORS}

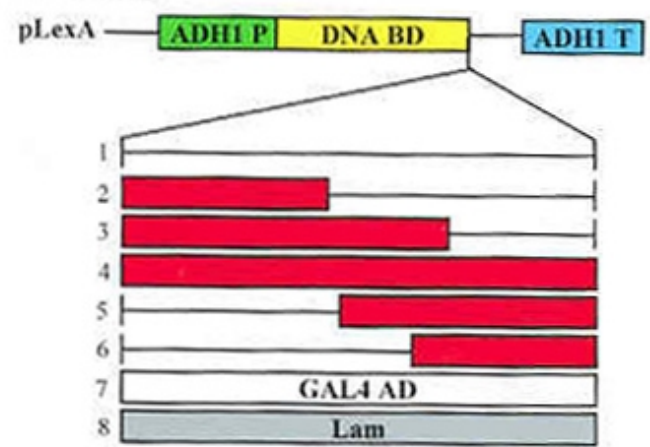

B
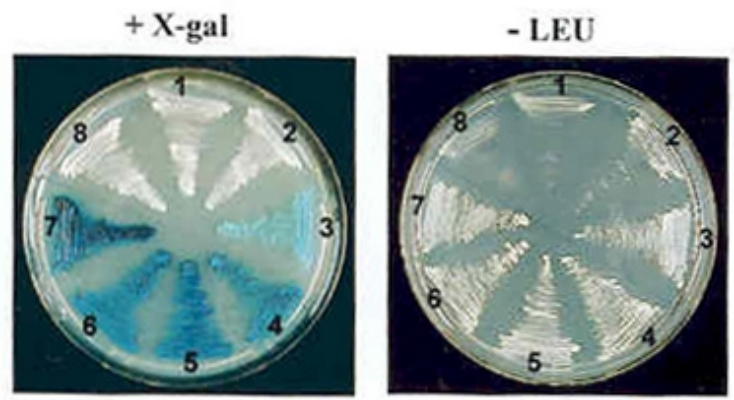

C

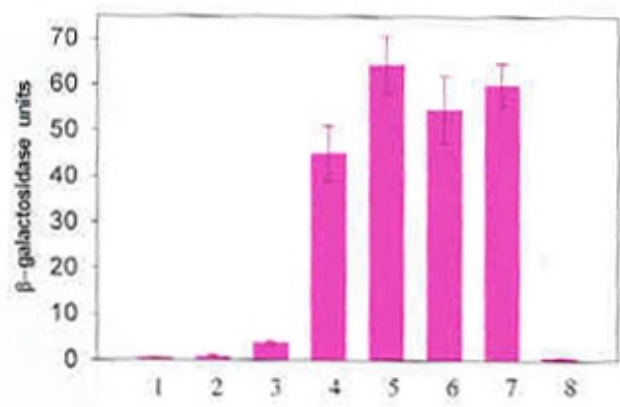

Fig. 3. Transcriptional activation analysis of PPI1 in yeast. A, Diagram of the reporter construct. B, LexA-dependent transactivation of PPI1 in yeast cells. C, Transcriptional activation activity of PPI1 in yeast cells analyzed using $o$-nitrophenyl $\beta$-D-galactopyranoside (ONPG) as a substrate. 1, LexA; 2, LexA-PPI1N1 (amino acids at position 1 to 68); 3 , LexA-PPI1N2 (position 1 to 115); 4, LexA-PPI1F (position 1 to 170); 5 , LexA-PPI1C1 (position 81 to 170); 6, LexA-PPI1C2 (position 110 to 170); 7, LexA-GAL4; and 8, LexA-Lam. One unit of $\beta$-galactosidase is defined as the amount that hydrolyzes $1 \mu \mathrm{mol}$ of ONPG to $O$-nitrophenol and D-galactose per min per cell. Data points are means of three replicates with standard error. 
cleus (Fig. 2). The putative NLS sequence of PPI1 $\left({ }^{33}\right.$ KRMISNRESARRSRMRK $\left.{ }^{49}\right)$ is a basic domain within the $\mathrm{N}$ terminal region of the protein, and it is a bipartite NLS by two basic amino acids ( $\mathrm{K}$ and $\mathrm{R}$ ) at each end. The amino acid sequence alignment of the basic domains of 11 plant bZIP proteins reveals a highly conserved motif of 17 consecutive amino acids, KRxxSNRESARRSRx[R/K]K. It is possible that the dual function of nuclear targeting and DNA binding is conserved in all members of the bZIP family (Varagona and Raikhel 1994).

Recent studies have identified several families of transcription factors that are possibly involved in the plant defense responses. These include W-box-binding WRKY proteins (Wang et al. 1998; Yu et al. 2001), Myb-like proteins (Sugimoto et al. 2000; Yang and Klessig 1996), ethylene-response elementbinding proteins (Büttner and Singh 1997; Park et al. 2001; Zhou et al. 1997), bZIP proteins (Büttner and Singh 1997; Després et al. 2000; Niggeweg et al. 2000; Zhang et al. 1999), and NAC proteins (Ren et al. 2000; Xie et al. 1999; S. J. Lee, S. Kim, S. Y. Yi, S. K. Oh, J. S. Lee, M.-C. Suh, K.-H. Paek, D. Choi, and B.-D. Kim, unpublished data). However, responses by these factors are not limited to pathogens. Most of the transcription factors may be connected and regulated by a network of signals. Combinatorial interactions among transcription factors may play an important role in mediating plant responses to abiotic/biotic signaling cross-talk (Singh 1998). Since PPII is only induced by pathogens and not by abiotic treatments, it may be involved in a distinct gene regulation pathway that involves factors different from those of other regulatory pathways.

Taken together, the data presented in this study strongly indicate that PPI1 is a transcription factor probably involved in the

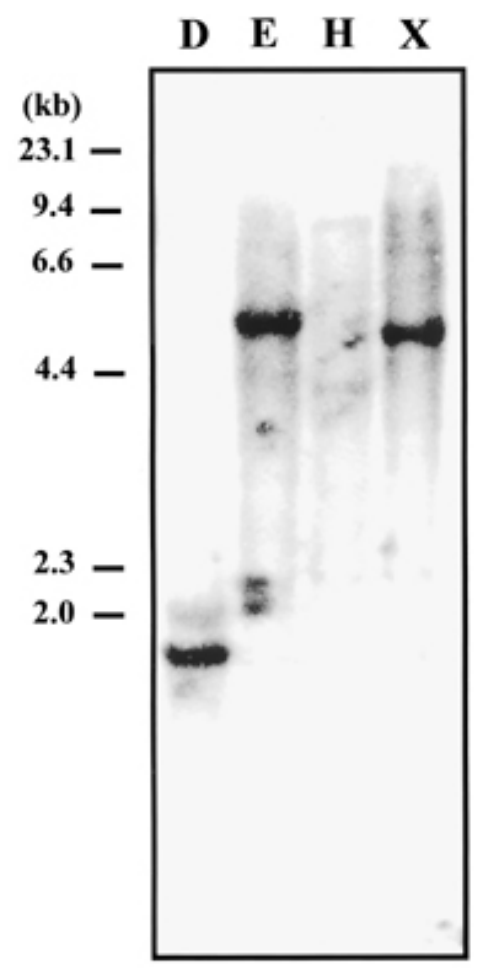

Fig. 4. Southern blot analysis of pepper genomic DNA. Genomic DNA (20 $\mu \mathrm{g}$ per lane) from pepper leaves was digested with DraI (D), EcoRI (E), HindIII (H), or XbaI (X) and then fractionated by electrophoresis on an $0.8 \%$ agarose gel. The blot was hybridized with the full-length PPII cDNA. The probe was prepared using the random primed DNA labeling method (Feinberg and Vogelstein 1983). Southern blot analysis was performed according to previously reported methods (Church and Gilbert 1984). transcriptional activation that occurs during pathogen attack. It will be important to determine the biological role of PPI1 and its place in the hierarchy of plant defense signaling. Currently, we are generating transgenic tobacco plants with increased or reduced expression of PPII to study its functional role in plant defense.

\section{MATERIALS AND METHODS}

Plant materials and pathogen inoculation.

C. chinense PI257284, carrying the $L^{3}$ resistance gene against the $\mathrm{P}_{1,2}$ pathotype of PMMV, was used for the isolation and expression analyses of genes induced by PMMV. The $L^{3}$ gene confers resistance to the $\mathrm{P}_{1,2}$ pathotype of PMMV (Berzal-Herranz et al. 1995; Boukema 1982). For the induction of HR, leaves from 7- to 8-week-old C. chinense PI257284 were inoculated with sap prepared from $N$. benthamiana leaves infected with PMMV and incubated at $25^{\circ} \mathrm{C}$. As a control, leaves were mechanically wounded using Carborundum. To investigate the temporal expression of the PPIl gene during a nonhost incompatible interaction, leaves from 7- to 8-week-old C. annuum cv. Bukang were inoculated by syringe infiltration with $P$. syringae pv. syringae $61\left(1 \times 10^{8} \mathrm{CFU} \mathrm{ml^{-1 }}\right)$. Two nearisogenic pepper cultivars used to investigate the temporal expression of the PPII gene were ECW ( $b s 2 / b s 2$, susceptible line) and ECW-20R (Bs2/Bs2, resistant line). Bacterial suspensions (approximately $2 \times 10^{8} \mathrm{CFU} \mathrm{ml}^{-1}$ ) of $X$. campestris $\mathrm{pv}$. vesicatoria race 3 ( $a v r B s 2)$ were used for infiltration. The infiltrated area of resistant plants developed an HR clearly different from that of susceptible plants within $24 \mathrm{~h}$ postinfiltration. The infiltrated leaves were harvested at various times and immediately frozen in liquid nitrogen for further analyses.

SSH.

The subtraction was performed with the polymerase chain reaction (PCR)-select cDNA subtraction kit (Clontech) according to the manufacturer's instructions. As the tester, cDNA from pepper leaves sampled 3 days after inoculation with PMMV and undergoing the initial HR was synthesized using Avian myeloblastosis virus (AMV) reverse transcriptase while, for the driver, cDNA from noninoculated pepper leaves was synthesized. To generate blunt-ended cDNA fragments that are optimal for subtraction and necessary for adaptor ligation, the tester cDNA was digested with RsaI and then ligated to the adaptors as recommended by the manufacturer. After the subtractive hybridization, the subtracted cDNAs were selectively amplified with nested PCR primers to enrich differentially expressed sequences. The amplified fragments were cloned into the pGEM-T easy vector (Promega, Madison, WI, U.S.A.), and the cloned fragments were sequenced with an automatic DNA sequencer (ABI3700; Applied Biosystems, Foster City, CA, U.S.A.). Sequence data were analyzed with BLAST, PSORT, and CLUSTALW programs.

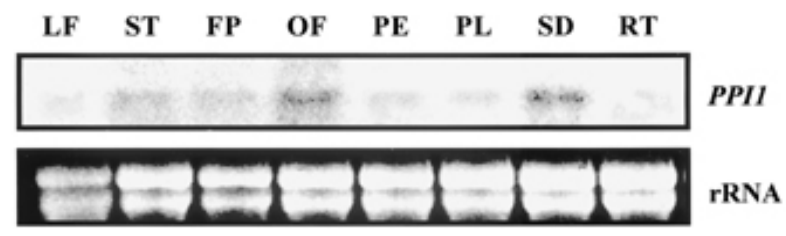

Fig. 5. Tissue-specific expression of the $P P I 1$ gene in pepper. Total RNA was extracted from leaves (LF), stems (ST), flower primordia (FP), open flowers (OF), fruit pericarps (PE), fruit placenta (PL), seeds (SD), and roots (RT). The probe detected transcripts of approximately $1.2 \mathrm{~kb}$ in size corresponding to PPII mRNA. 
Subcellular localization analysis of the PPI1-smGFP protein.

A chimeric fusion construct, PPII-smGFP, was generated to enable the subcellular localization of the PPI1 protein to be determined. A full-length PPII ORF without the termination codon was prepared by PCR amplification with the PPII cDNA in pBluescript SK-phagemid as a template. Two PPII gene-specific oligonucleotide primers, 5'-GCGCGGATCCATGGCTTCTTCAAGTGGT-3' and 5'-GCGCGGATCCGTACTGCAAGACATGTGC-3', containing BamHI sites, were synthesized and used to amplify the PPII ORF. The PCR-amplified product was digested with $B a m \mathrm{HI}$ and purified from an agarose gel and then inserted into the BamHI site of the plasmid pSMGFP (David and Vierstra 1996). Subcellular localization of the PPI1-smGFP fusion construct was performed as previously described (Lee et al. 2001).
Yeast transactivation assay.

The EcoRI-XhoI restriction fragments of the truncated forms of PPII were ligated into the EcoRI-XhoI site of pLexA (Clontech) to make in-frame fusions with the LexA DNA-binding domain. The resulting plasmids were named pLexA-PPI1F (amino acids at position 1 to 170), pLexA-PPI1N1 (position 1 to 68), pLexA-PPI1N2 (position 1 to 115), pLexA-PPI1C1 (position 81 to 170), and pLexA-PPI1C2 (position 110 to 170). These were cotransformed into the yeast strain, EGY48, with p8op-lacZ, which contains a $L a c Z$ reporter gene under the control of a LexA operator. For controls, pLexA, pLexA-Lam, and pLexA-GAL4 were used. Enzymatic assays for $\beta$-galactosidase in the yeast clones containing LexA fusion proteins were performed using $O$ nitrophenyl $\beta$-D-galactopyranoside (ONPG) as a substrate, according to the manufacturer's instructions (Clontech).

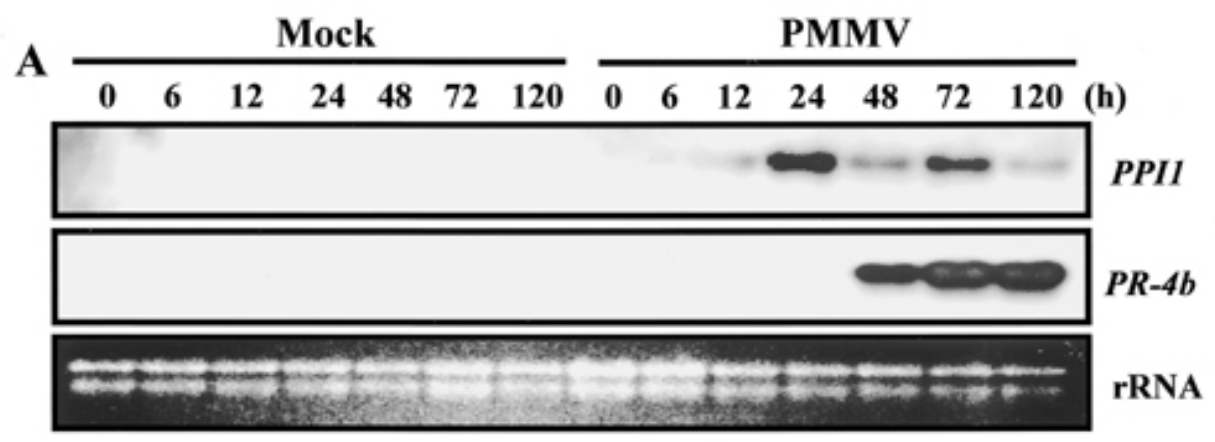

B

P. syringae pv. syringae 61

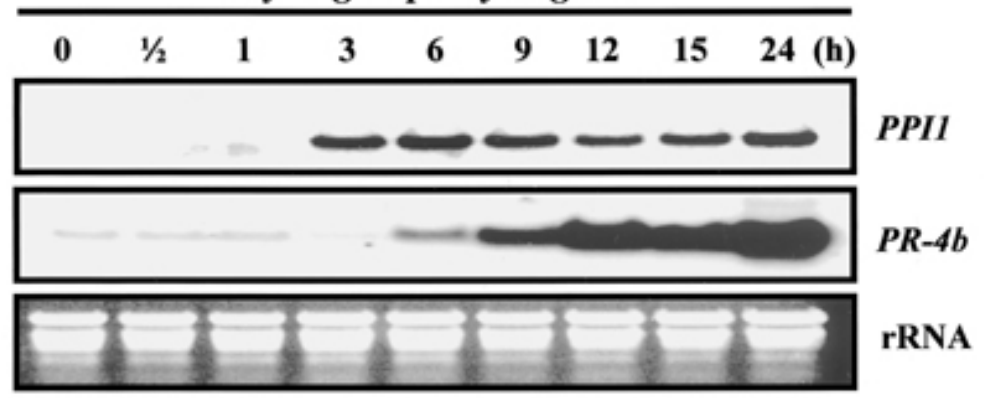

C

X. campestris pv. vesicatoria race 3 (avrBs2)

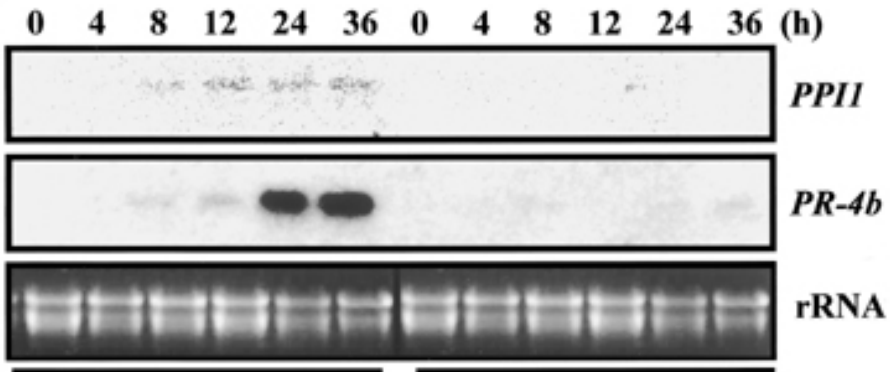

ECW-20R (Bs2/Bs2)

ECW (bs2/bs2)

Fig. 6. Induction of PPI1 by pathogens in pepper. A, Induction of PPII by Pepper mild mottle virus (PMMV) (pathotype $\mathrm{P}_{1,2}$ ) in Capsicum chinense PI257284 that carries the $L^{3}$ resistance gene. Leaf samples were harvested at indicated time points and total RNA was extracted. Upper panels and lower panels show hybridizations with $P P I I$ and $P R-4 b$ (a positive marker for pathogen treatment) probes, respectively. Twenty micrograms of total RNA was used per lane. B, Induction of PPII by Pseudomonas syringae pv. syringae 61 in Capsicum annuum cv. Bukang. C, Expression pattern of PPII in two near-isogenic lines (C. аппиит ECW-20R, resistant; $C$. annuит ECW, susceptible) inoculated with Xanthomonas campestris pv. vesicatoria race 3. 
Genomic DNA blot analysis.

Genomic DNA was isolated from mature leaves of $C$. chinense PI257284 as described (Lee et al. 2001). DNA was treated with RNase, and 20- $\mu$ g samples were digested to completion with DraI, EcoRI, HindIII, or XbaI. The digested genomic DNA was separated by electrophoresis on an $0.8 \%$ agarose gel, denatured, and blotted onto a nylon membrane (Amersham Pharmacia Biotech, Piscataway, NJ, U.S.A.). Southern blotting was performed as described previously (Church and Gilbert 1984), and the membranes were hybrid- ized with a full-length $P P I 1$ cDNA probe labeled with ${ }^{32} \mathrm{P}(5 \times$ $10^{6}$ disintegrations per $\left.\min [\mathrm{dpm}]\right)$.

\section{Chemical treatments.}

For chemical compound treatments, SA was dissolved in water at a concentration of $5 \mathrm{mM}$; MeJA and ethephon were dissolved in $10 \%$ acetone at concentrations of $100 \mu \mathrm{M}$ and $5 \mathrm{mM}$, respectively; $\mathrm{ABA}$ was dissolved in $0.1 \%$ ethanol at a final concentration of $100 \mu \mathrm{M}$; and $\mathrm{H}_{2} \mathrm{O}_{2}$ was diluted in water at a final concentration of $5 \mathrm{mM}$. These chemicals were sprayed
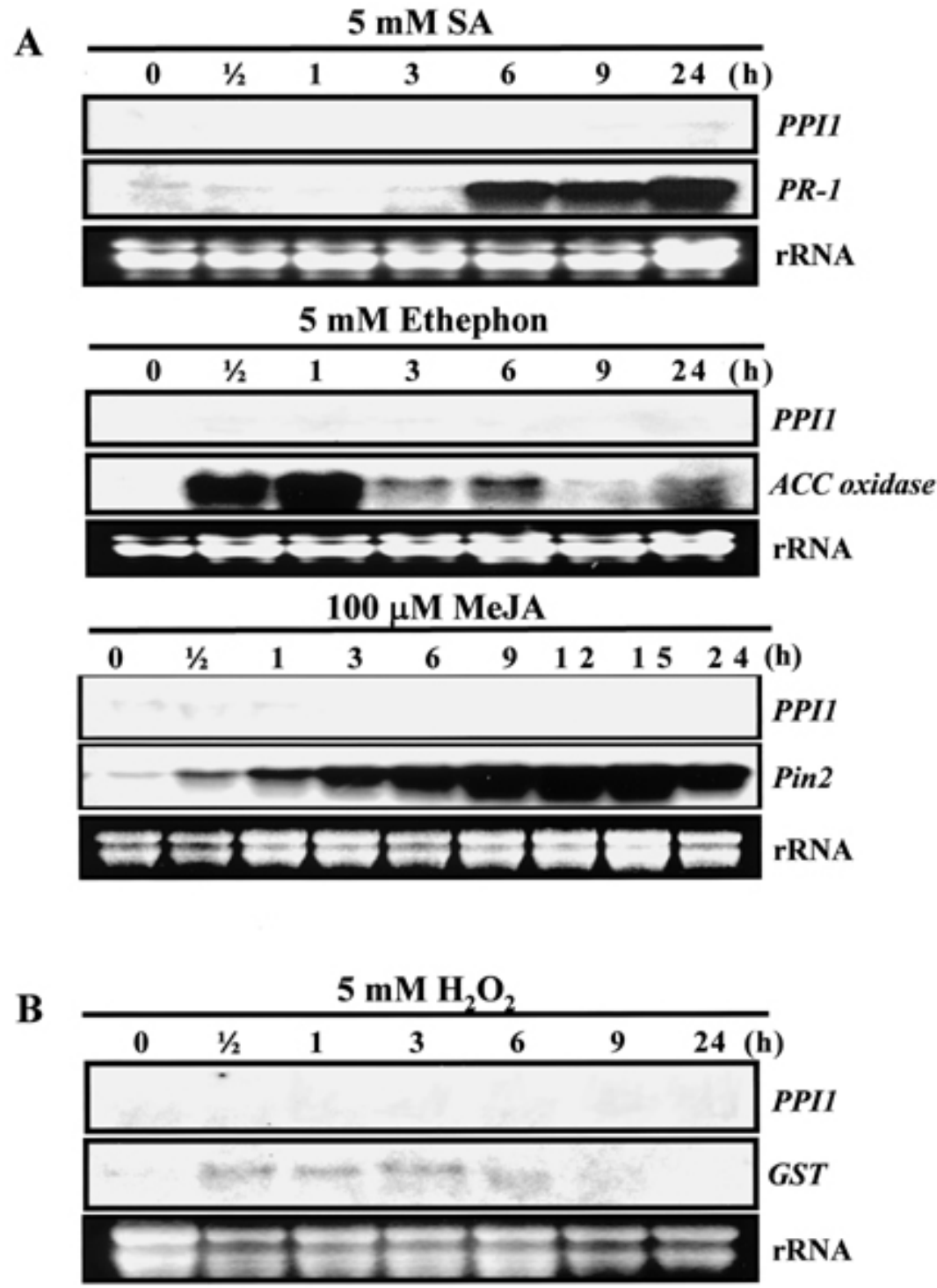

$100 \mu \mathrm{M}$ ABA

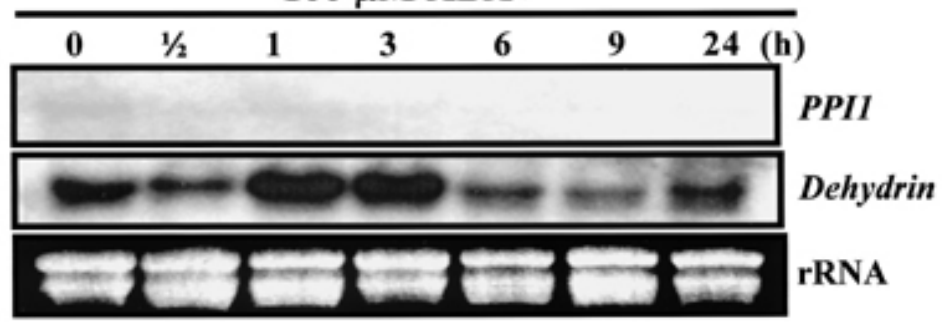

Fig. 7. PPI1 gene expression in response to abiotic treatments. A, Expression patterns of the PPI1 gene after exogenous treatment with salicylic acid (SA), ethephon, or methyl jasmonate (MeJA). Total RNA was extracted at different time points from pepper leaves treated with 5 mM SA, 5 mM ethephon, or $100 \mu \mathrm{M}$ MeJA. PR-1, ACC oxidase, and Pin2 genes were used as positive markers for the SA, ethephon, and MeJA treatments, respectively. B, PPII expression in response to $5 \mathrm{mM} \mathrm{H}_{2} \mathrm{O}_{2}$ or $100 \mu \mathrm{M}$ abscisic acid (ABA). GST and Dehydrin were used as positive markers for $\mathrm{H}_{2} \mathrm{O}_{2}$ and $\mathrm{ABA}$ treatments, respectively. 
onto the matured leaves of $C$. chinense PI257284. For all the experiments, leaves were pooled from several plants grown under the same conditions, quickly frozen in liquid nitrogen, and stored at $-70^{\circ} \mathrm{C}$ until used.

\section{Gene expression analysis.}

Total RNA was extracted from different tissues of $C$. chinense PI257284 by a previously described method (Choi et al. 1996). Twenty micrograms of total RNA was denatured and electrophoresed with $1.0 \%$ agarose gels containing formaldehyde and transferred onto nylon membranes (Amersham Pharmacia Biotech). The membranes were hybridized with ${ }^{32} \mathrm{P}$ labeled $\left(5 \times 10^{6} \mathrm{dpm}\right)$ probes.

\section{ACKNOWLEDGMENTS}

The authors would like to thank K.-H. Paek (Plant Molecular Biology and Genetics Laboratory, Graduate School of Biotechnology, Korea University, Seoul, Korea) for critically reviewing the manuscript and S.-Y. Kim for technical assistance (Genome Research Center, Korean Research Institute of Bioscience and Biotechnology). This research was supported by a grant (RF003202-01) to C. H. Harn from the Plant Diversity Research Center of 21st Frontier Research Program funded by the Ministry of Science and Technology of the Korean government.

\section{LITERATURE CITED}

Aguan, K., Sugawara, K., Suzuki, N., and Kusano, T. 1993. Low-temperature-dependent expression of a rice gene encoding a protein with a leucine-zipper motif. Mol. Gen. Genet. 240:1-8.

Albani, D., Hammond-Kosack, M. C., Smith, C., Conlan, S., Colot, V., Holdsworth, M., and Bevan, M. W. 1997. The wheat transcriptional activator SPA: A seed-specific bZIP protein that recognizes the GCN4like motif in the bifactorial endosperm box of prolamin genes. Plant Cell 9:171-184.

Berzal-Herranz, A., de la Cruz, A., Tenllado, F., Díaz-Ruíz, J. R., López, L., Sanz, A. I., Vaquero, C., Serra, M. T., and García-Luque, I. 1995. The Capsicum $\mathrm{L}^{3}$ gene-mediated resistance against the tobamoviruses is elicited by the coat protein. Virology 209:498-505.

Boukema, I. W. 1982. Resistance to TMV in Capsicum chacoense Hunz. is governed by an allele of the L-locus. Capsicum Newsl. 3:47-48.

Büttner, M., and Singh, K. B. 1997. Arabidopsis thaliana ethyleneresponsive element binding protein (AtEBP), an ethylene-inducible, GCC box DNA-binding protein interacts with an ocs element binding protein. Proc. Natl. Acad. Sci. U.S.A. 94:5961-5966.

Chern, M. S., Eiben, H. G., and Bustos, M. M. 1996. The developmentally regulated bZIP factor ROM1 modulates transcription from lectin and storage protein genes in bean embryos. Plant J. 10:135-148.

Choi, D., Kim, H. M., Yun, H. K., Park, J. A., Kim, W. T., and Bok, S. H. 1996. Molecular cloning of a metallothionein-like gene from Nicotiana glutinosa $\mathrm{L}$. and its induction by wounding and tobacco mosaic virus infection. Plant Physiol. 112:353-359.

Chuang, C. F., Running, M. P., Williams, R. W., and Meyerowitz, E. M. 1999. The PERIANTHIA gene encodes a bZIP protein involved in the determination of floral organ number in Arabidopsis thaliana. Genes Dev. 13:334-344.

Church, G. M., and Gilbert, W. 1984. Genomic sequencing. Proc. Natl. Acad. Sci. U.S.A. 81:1991-1995.

David, S. J., and Vierstra, R. D. 1996. Soluble derivatives of green fluorescent protein (GFP) for use in Arabidopsis thaliana. Weeds World 3:43-48.

Després, C., DeLong, C., Glaze, S., Liu, E., and Fobert, P. R. 2000. The Arabidopsis NPR1/NIM1 protein enhances the DNA binding activity of a subgroup of the TGA family of bZIP transcription factors. Plant Cell 12:279-290.

Dong, X. 1998. SA, JA, ethylene, and disease resistance in plants. Curr. Opin. Plant Biol. 1:316-323.

Dröge-Laser, W., Kaiser, A., Lindsay, W. P., Halkier, B. A., Loake, G. J., Doerner, P., Dixon, R. A., and Lamb, C. 1997. Rapid stimulation of a soybean protein-serine kinase that phosphorylates a novel bZIP DNA-binding protein, G/HBF-1, during the induction of early transcription-dependent defenses. EMBO (Eur. Mol. Biol. Organ.) J. 16:726-738.

Feinberg, A. P., and Vogelstein, B. 1983. A technique for radiolabeling a
DNA restriction endonuclease fragment to high specific activity. Anal. Biochem. 72:248-254.

Foster, R., Izawa, T., and Chua, N. H. 1994. Plant bZIP proteins gather at ACGT elements. FASEB (Fed. Am. Soc. Exp. Biol.) J. 8:192-200.

Fukazawa, J., Sakai, T., Ishida, S., Yamaguchi, I., Kamiya, Y., and Takahashi, Y. 2000. Repression of shoot growth, a bZIP transcriptional activator, regulates cell elongation by controlling the level of gibberellins. Plant Cell 12:901-915.

Görlich, D. 1997. Nuclear protein import. Curr. Opin. Cell Biol. 9:412419.

Lee, S. J., Suh, M.-C., Kim, S., Kwon, J.-K., Kim, M., Paek, K.-H., Choi, D., and Kim, B.-D. 2001. Molecular cloning of a novel pathogeninducible cDNA encoding a putative acyl-CoA synthetase from Capsicum annuum L. Plant Mol. Biol. 46:661-671.

Menkens, A. E., Schindler, U., and Cashmore, A. R. 1995. The G-box: A ubiquitous regulatory DNA element in plants bound by the GBF family of bZIP proteins. Trends Biochem. Sci. 20:506-510.

Meshi, T., and Iwabuchi, M. 1995. Plant transcription factors. Plant Cell Physiol. 36:1405-1420.

Nakagawa, H., Ohmiya, K., and Hattori, T. 1996. A rice bZIP protein, designated OSBZ8, is rapidly induced by abscisic acid. Plant J. 9:217227.

Niggeweg, R., Thurow, C., Kegler, C., and Gatz, C. 2000. Tobacco transcription factor TGA2.2 is the main component of as-1-binding factor ASF-1 and is involved in salicylic acid- and auxin-inducible expression of as-1-containing target promoters. J. Biol. Chem. 275:1989719905.

Oyama, T., Shimura, Y., and Okada, K. 1997. The Arabidopsis HY5 gene encodes a bZIP protein that regulates stimulus-induced development of root and hypocotyl. Genes Dev. 11:2983-2995.

Park, J. M., Park, C. J., Lee, S. B., Ham, B. K., Shin, R., and Paek, K.-H. 2001. Overexpression of the tobacco Tsil gene encoding an EREBP/AP2-type transcription factor enhances resistance against pathogen attack and osmotic stress in tobacco. Plant Cell 13:10351046.

Ren, T., Qu, F., and Morris, T. J. 2000. HRT gene function requires interaction between a NAC protein and viral capsid protein to confer resistance to turnip crinkle virus. Plant Cell 12:1917-1925.

Reymond, P., and Farmer, E. E. 1998. Jasmonate and salicylate as global signals for defense gene expression. Curr. Opin. Plant Biol. 1:404-411.

Riechmann, J. L., and Ratcliffe, O. J. 2000. A genomic perspective on plant transcription factors. Curr. Opin. Plant Biol. 3:423-434.

Rook, F., Weisbeek, P., and Smeekens, S. 1998. The light-regulated Arabidopsis bZIP transcription factor gene ATB2 encodes a protein with an unusually long leucine zipper domain. Plant Mol. Biol. 37:171-178.

Rushton, P. J., and Somssich, I. E. 1998. Transcriptional control of plant genes responsive to pathogens. Curr. Opin. Plant Biol. 1:311-315.

Schwechheimer, C., Smith, C., and Bevan, M. W. 1998. The activities of acidic and glutamine-rich transcriptional activation domains in plant cells: Design of modular transcription factors for high-level expression. Plant Mol. Biol. 36:195-204.

Singh, K. B. 1998. Transcriptional regulation in plants: The importance of combinatorial control. Plant Physiol. 118:1111-1120.

Sprenger-Haussels, M., and Weisshaar, B. 2000. Transactivation properties of parsley proline-rich bZIP transcription factors. Plant J. 22:1-8.

Stanković, B., Vian, A., Henry-Vian, C., and Davies, E. 2000. Molecular cloning and characterization of a tomato cDNA encoding a systemically wound-inducible bZIP DNA-binding protein. Planta 212:60-66.

Strathmann, A., Kuhlmann, M., Heinekamp, T., and Dröge-Laser, W. 2001. BZI-1 specifically heterodimerises with the tobacco bZIP transcription factors BZI-2, BZI-3/TBZF and BZI-4, and is functionally involved in flower development. Plant J. 28:397-408.

Sugimoto, K., Takeda, S., and Hirochika, H. 2000. MYB-related transcription factor NtMYB2 induced by wounding and elicitors is a regulator of the tobacco retrotransposon Ttol and defense-related genes. Plant Cell 12:2511-2527.

Tai, T. H., Dahlbeck, D., Clark, E. T., Gajiwala, P., Pasion, R., Whalen, M. C., Stall, R. E., and Staskawicz, B. J. 1999. Expression of the Bs2 pepper gene confers resistance to bacterial spot disease in tomato. Proc. Natl. Acad. Sci. U.S.A. 96:14153-14158.

Varagona, M. J., and Raikhel, N. V. 1994. The basic domain in the bZIP regulatory protein Opaque2 serves two independent functions: DNA binding and nuclear localization. Plant J. 5:207-214.

Wang, Z., Yang, P., Fan, B., and Chen, Z. 1998. An oligo selection procedure for identification of sequence-specific DNA-binding activities associated with the plant defense response. Plant J. 16:515-522. 
Xie, Q., Sanz-Burgos, A. P., Guo, H., Garcia, J. A., and Gutierrez, C. 1999. GRAB proteins, novel members of the NAC domain family, isolated by their interaction with a geminivirus protein. Plant Mol. Biol. 39:647-656

Yang, Y., and Klessig, D. F. 1996. Isolation and characterization of a tobacco mosaic virus-inducible myb oncogene homolog from tobacco. Proc. Natl. Acad. Sci. U.S.A. 93:14972-14977.

Yin, Y., Zhu, Q., Dai, S., Lamb, C., and Beachy, R. N. 1997. RF2a, bZIP transcriptional activator of the phloem-specific rice tungro bacilliform virus promoter, functions in vascular development. EMBO (Eur. Mol. Biol. Organ.) J. 16:5247-5259.

Yu, D., Chen, C., and Chen, Z. 2001. Evidence for an important role of WRKY DNA binding proteins in the regulation of NPRl gene expression. Plant Cell 13:1527-1539.

Zhang, Y., Fan, W., Kinkema, M., Li, X., and Dong, X. 1999. Interaction of NPR1 with basic leucine zipper protein transcription factors that bind sequences required for salicylic acid induction of the $P R-1$ gene.
Proc. Natl. Acad. Sci. U.S.A. 96:6523-6528.

Zhou, J., Tang, X., and Martin, G. B. 1997. The Pto kinase conferring resistance to tomato bacterial speck disease interacts with proteins that bind a cis-element of pathogenesis-related genes. EMBO (Eur. Mol. Biol. Organ.) J. 16:3207-3218.

Zhou, J.-M., Trifa, Y., Silva, H., Pontier, D., Lam, E., Shah, J., and Klessig, D. F. 2000. NPR1 differentially interacts with members of the TGA/OBF family of transcription factors that bind an element of the $P R-1$ gene required for induction by salicylic acid. Mol. Plant-Microbe Interact. 13:191-202.

\section{AUTHOR-RECOMMENDED INTERNET RESOURCES}

BLAST program: http://www.ncbi.nlm.nih.gov/BLAST/ CLUSTALW program: http://www2.ebi.ac.uk/clustalw/ PSORT program: http://psort.nibb.ac.jp/ 